\title{
Experimental Study on Dynamic Compression Characteristics of Red Sandstone under Wetting-Drying Cycles
}

\author{
Bin Du $\left(\mathbb{D},{ }^{1,2,3}\right.$ Haibo Bai, ${ }^{2}$ Minglei Zhai, ${ }^{2}$ and Shixin $\mathrm{He}^{2}$ \\ ${ }^{1}$ School of Architectural Construction, Jiangsu Vocational Institute of Architectural Technology, Xuzhou, Jiangsu 221116, China \\ ${ }^{2}$ State Key Laboratory for Geomechanics and Deep Underground Engineering, China University of Mining and Technology, \\ Xuzhou, Jiangsu 221116, China \\ ${ }^{3}$ Jiangsu Collaborative Innovation Center for Building Energy Saving and Construction Technology, Xuzhou, \\ Jiangsu 221116, China
}

Correspondence should be addressed to Bin Du; dubin_china@163.com

Received 4 October 2020; Revised 3 November 2020; Accepted 3 December 2020; Published 14 December 2020

Academic Editor: Hualei Zhang

Copyright $\odot 2020$ Bin Du et al. This is an open access article distributed under the Creative Commons Attribution License, which permits unrestricted use, distribution, and reproduction in any medium, provided the original work is properly cited.

To study the influence of wetting-drying cycles on dynamic mechanical properties of rock masses, the impact compression tests of red sandstone samples were carried out by using a split Hopkinson pressure bar (SHPB) apparatus with a diameter of $50 \mathrm{~mm}$. The results showed that under the same number of wetting-drying cycles, the dynamic compressive strength of red sandstone increased exponentially with the strain rate, and the sensitivity of the strain rate decreased with the increase of wetting-drying cycles. The deterioration effect of wetting-drying cycles was significant, and the dynamic and static compressive strength decreased with the increase of wetting-drying cycles; the higher the strain rate, the stronger the sensitivity to wetting-drying cycles. Besides, the influence of wetting-drying cycles and strain rate was comprehensively studied, and the equation of dynamic compressive strength of red sandstone was obtained. After different wetting-drying cycles, the fractal characteristics of red sandstone dynamic fragmentation were obvious, and the fractal dimension was 2.02-2.80, and the fractal dimension increased logarithmically with the strain rate. Finally, the internal microstructure of red sandstone after different wetting-drying cycles was analyzed, and the degradation mechanism of the rock by the cycles was discussed.

\section{Introduction}

The mechanical properties of rocks are not only related to mineral composition, structural plane development, and its conditions but also directly related to the occurrence environment. Water is one of the geological conditions of rock mass engineering, and the water-rock coupling can degrade rock mechanical properties [1-4]. This issue has been highlighted and many important achievements have been made [5-11]. Since the coal mining is gradually transferred to the deep mining, rock dynamics problem under the mechanical excavation, blasting, rock burst, earthquake, and other dynamic loads are widely involved, and the threat of high-stress disturbance to the safety production in coal mines cannot be ignored [12-16]. Therefore, it is of great practical significance to study the variation law and failure mechanism of rock mechanical properties by hydrodynamic coupling.

In the aspect of water-rock dynamic coupling, many studies have been conducted at home and abroad. Through the split Hopkinson pressure bar (SHPB) test device, Ruhbin and Ahrens [17] studied the dynamic tensile strength of granite under dry and water-saturated conditions. The results showed that water-saturated granite is more difficult to break. Wang et al. [18] carried out a dynamic impact test on sandstone under natural air-drying and saturated conditions and found that the dynamic strength of sandstone is slightly different under the two conditions, and the sensitivity of strain rate in the water-saturated sandstone is stronger. In order to study the coupled effects of water and high strain rate on the mechanical behavior and microstructures of sandstone, Cai et al. $[19,20]$ conducted a series of dynamic 
compressive tests on oven-dried and water-saturated sandstone core samples using a split Hopkinson pressure bar. Zhou et al. [21] investigated the effect of water content on mechanical properties of sandstone in both saturation and drying processes and found that the tensile strength of samples with the same water content was different in saturation and drying processes. Wang et al. [22] conducted uniaxial impact tests on natural, soaked, and saturated samples and analyzed the dynamic mechanical properties of red sandstone and the energy evolution mechanism before and after damage and failure under the hydrodynamic coupling. In the abovementioned studies, the two states of drying and water saturation in samples are just considered, which also limits the application of the research results in some fields. Due to the rise and fall of groundwater level or seasonal changes, rock masses are often in a periodic humid environment, which increases the weathering degree of the rock mass. Therefore, it is necessary to systematically study the dynamic properties of rock under the action of wetting-drying cycles. Zhou et al. $[23,24]$ conducted dynamic compression and dynamic tensile tests on sandstone rock samples with different wetting-drying cycles and found that the dynamic mechanical properties of sandstone have deteriorated to different degrees. Due to the discrepancy of rock composition, the mechanical properties of different rock differ in their sensitivity to the wetting-drying cycles. There are still many problems to be studied in exploring the evolution law of dynamic mechanical properties of different rocks under wetting-drying cycles.

In this paper, the impact compression tests of red sandstone samples after different cycles were carried out by the SHPB apparatus with a diameter of $50 \mathrm{~mm}$. The dynamic compression properties and fragmentation evolution law of red sandstone under the combined action of wetting-drying cycles and the strain rate were analyzed. Besides, the degradation mechanism of red sandstone was analyzed from the microscopic point of view.

\section{Experimental Processes}

2.1. Sample Preparation. The red sandstone samples were collected from Linyi, Shandong Province. The samples were brown-red, with fine-grained structure, uniform particles, and good structural integrity. The main mineral components were quartz and feldspar. The rock samples used in the test were taken from the same rock. Through the core drilling, cutting, and grinding, the cylindrical samples were obtained. The surface flatness error was controlled within $0.02 \mathrm{~mm}$; the parallelism error of upper and lower end faces was controlled within $0.05 \mathrm{~mm}$. The end face was perpendicular to the axis of the sample, and the deviation was not more than $0.25^{\circ}$. According to the test method recommended by ISRM (International Society for Rock Mechanics), the specimen size for the dynamic compression test is $\varphi 50 \mathrm{~mm} \times 25 \mathrm{~mm}$ and that for the static compression test is $\varphi$ $50 \mathrm{~mm} \times 100 \mathrm{~mm}$. The basic physical and mechanical parameters of red sandstone are shown in Table 1, and the processed rock sample is shown in Figure 1.
2.2. SHPB Equipment. The split Hopkinson pressure bar (SHPB) system with a diameter of $50 \mathrm{~mm}$ was adopted in the dynamic impact compression test. The SHPB system was mainly composed of the load driving system, pressure bar system, energy absorption system, signal acquisition, and data processing system. The schematic diagram of the equipment system is shown in Figure 2. The punch, incident rod, transmission rod, and absorption rod in the test system were made of $40 \mathrm{Cr}$ alloy steel, with an elastic modulus of $210 \mathrm{GPa}$ and a density of $7800 \mathrm{~kg} / \mathrm{m}^{3}$. The length of incident rod was $2400 \mathrm{~mm}$, the length of transmission rod was $1400 \mathrm{~mm}$, and the diameter of both rods was $50 \mathrm{~mm}$. The punch was cylindrical, with a length of $290 \mathrm{~mm}$ and a section diameter of $36 \mathrm{~mm}$. The DH5960 ultra-dynamic signal acquisition instrument produced by Jiangsu Donghua was adopted in the data acquisition system.

2.3. Validation of Test Effectiveness. To obtain the reliable stress-strain relationship, waveform shaping technology was adopted in this test, that is, a square rubber sheet was pasted on the end face of the incident rod and punch (the side length and the thickness of the rubber sheet were $1 \mathrm{~cm}$ and $1 \mathrm{~mm}$ ). Figure 3 shows the SHPB test waveform of red sandstone after reshaping. It can be seen that there is no obvious waveform oscillation in the transmission process of stress wave, and the incident wave is sinusoidal, and the whole system conforms to the stress wave one-dimensional propagation hypothesis [25-27]. The rising edge of incident wave is extended effectively so that the rock sample has enough time to reach the stress equilibrium before failure. In addition, a layer of vaseline was evenly applied on the end face of the specimen and the rod to reduce the end friction effect of the contact position between the test and the rod end.

To ensure the validity of the dynamic compression test, there is an important premise, namely, the specimen can reach stress balance before failure. This point can be checked by comparing the stress on both sides of the sample in the compression process. As shown in Figure 3, the superposition of incident wave and reflected wave basically coincides with the transmitted wave, indicating that the axial force on both sides of the sample is the same in the dynamic compression stage. In this case, the axial inertia effect can be ignored [28-30]. It is proved that the stress on both sides of the rock sample has reached equilibrium, indicating that the test results are effective.

2.4. Wetting-Drying Cycle Design. The wetting-drying cycle was carried out by natural water absorption at room temperature and drying treatment in an oven. According to the Methods for Determining the Physical and Mechanical Properties of Coal and Rock-Part 5: Methods for Determining the Water Absorption of Coal and Rock (GB/ T23561.5-2009) [31], the red sandstone sample was put into a water container to absorb water freely for 24 hours and then put into an oven to dry for 24 hours. The abovementioned process is a wetting-drying cycle. To minimize the influence of temperature on rock mechanical properties, 
TABle 1: Physical and mechanical parameters of red sandstone.

\begin{tabular}{lcccc}
\hline Density $\left(\mathrm{kg} \cdot \mathrm{m}^{-3}\right)$ & P-wave velocity $\left({\left.\mathrm{m} \cdot \mathrm{s}^{-1}\right)}^{2620}\right.$ & Compressive strength $(\mathrm{MPa})$ & Tensile strength $(\mathrm{MPa})$ & Poisson ratio \\
\hline 2485 & 2620 & 78.2 & 4.82 & 0.22 \\
\hline
\end{tabular}

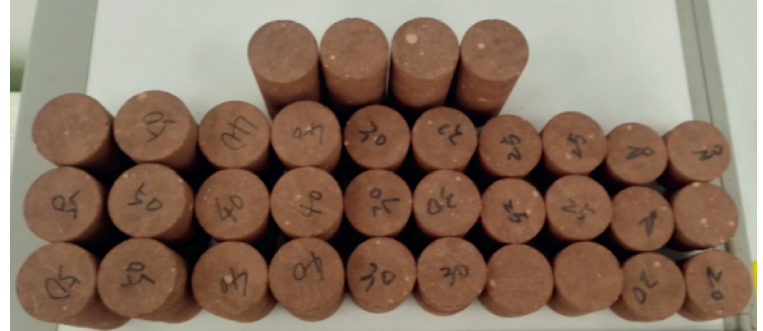

FIGURE 1: Red sandstone specimens.

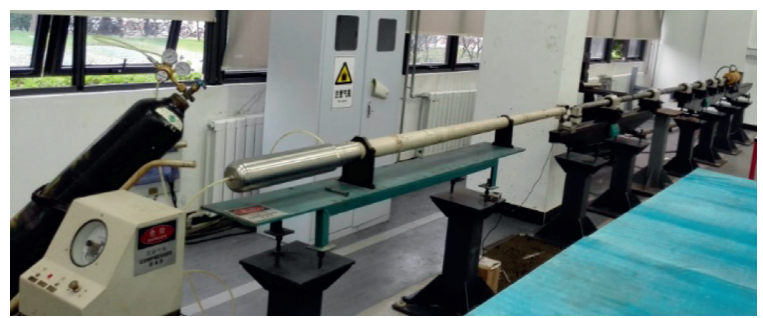

FIGURE 2: SHPB testing system.

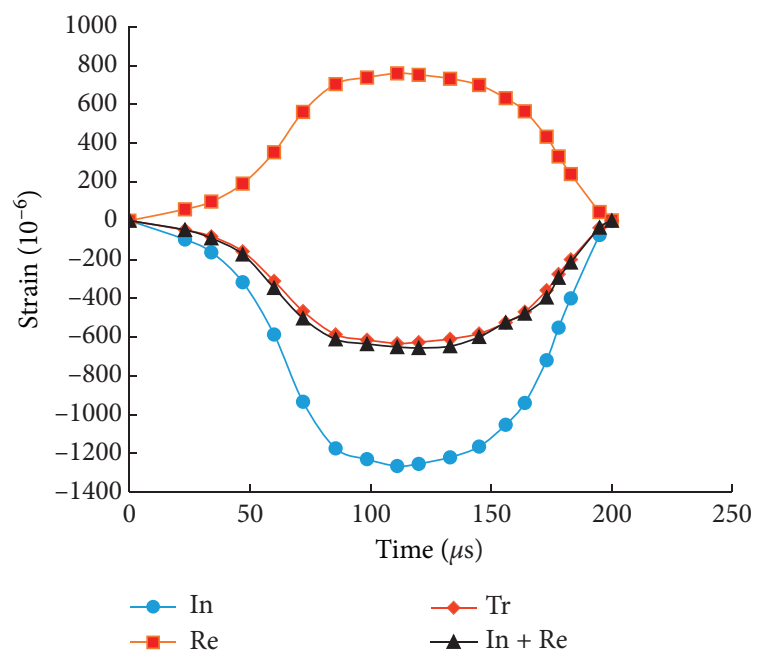

Figure 3: Verification of the typical SHPB waveform and stress uniformity.

the oven temperature was set at $60^{\circ} \mathrm{C}$. To ensure the full soaking of rock samples, plastic grids were placed at the interface between the rock sample and the container and the interface between the two layers of the rock sample. When the number of wetting-drying cycles reached the designed value, the rock samples were in the dry state and the dynamic impact test was conducted. In this experiment, 5 levels of wetting-drying cycles were designed, including 0 (dry state), $5,10,15$, and 20 cycles.

\section{Results and Analysis}

3.1. Static Mechanical Properties of Red Sandstone under Wetting-Drying Cycles. The static uniaxial compression test of red sandstone was carried out by the RMT-150B rock mechanics test system. The loading rate was set as $4 \times 10^{-3} \mathrm{~mm} / \mathrm{s}$ by displacement control. The uniaxial compression failure of the sample is shown in Figure 4.

Figure 5 shows the stress-strain curve of red sandstone under the uniaxial compression. The uniaxial compression failure of red sandstone after different wetting-drying cycles is a typical brittle failure, which is mainly manifested in the tensile shear failure mode; the rock sample is fractured in two parts with the failure surface. The stress-strain curve can be divided into three stages: initial compaction stage, elastic stage, and failure stage. With the increase of wetting-drying cycles, the uniaxial compressive strength and elastic modulus of rock samples gradually decrease, and the length of the compaction section and yield strain increase accordingly. This is because the deterioration effect of wetting-drying cycles results in the decrease of rock sample density and softening and the corresponding increase of Poisson's ratio.

3.2. Analysis of SHPB Test Results. In this test, different strain rates were provided for red sandstone samples by changing the input air pressure. Dynamic impact tests were carried out on rock samples under different wetting-drying cycles, and the strain rates were increased gradually. After a series of tests and stress equilibrium verification, the oscillograph of dynamic compressive stress of red sandstone under different strain rates and wetting-drying cycles was obtained. The dynamic mechanical parameters such as stress, strain, and strain rate were calculated by three-wave method.

3.2.1. Dynamic Compression Stress-Strain Curve. Due to space limitation, the dynamic compression stress-strain curve at the impact pressure of $0.25 \mathrm{MPa}$ is only given in Figure 6.

Before the peak stress, the stress-strain curve can be divided into three stages: compaction stage, linear elastic stage, and plastic yield stage. (1) Compaction stage: the compaction stage is mainly composed of two processes: the contact compaction of the compression bar and the compaction and closure of the internal pores of the rock. When the number of wetting-drying cycles is less than 10 , the compaction stage of the rock sample is not obvious; when the number of wetting-drying cycles is more than 10 , there is an obvious compaction stage in the initial loading stage due to the deterioration of the wetting-drying cycles. (2) Linear elastic section: the stress increases linearly with the strain, and the red sandstone shows elastic characteristics. With the increase of wetting-drying cycles, this elastic stage is gradually shortened. (3) Plastic yield stage: before reaching the 


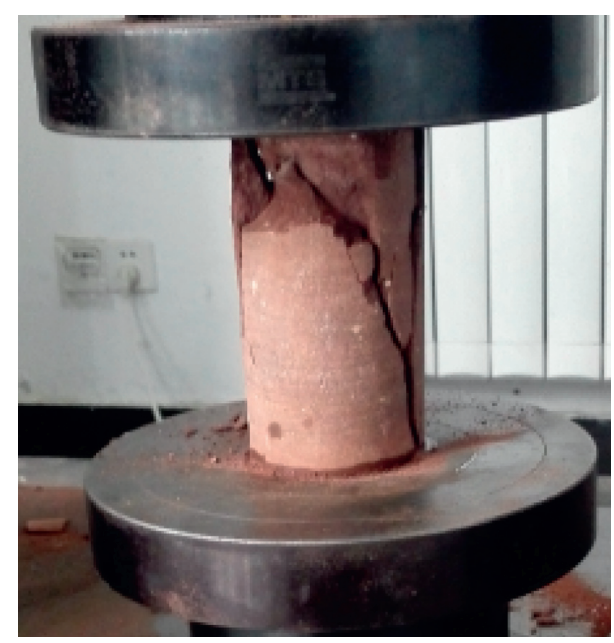

Figure 4: Static uniaxial compression test of red sandstone.

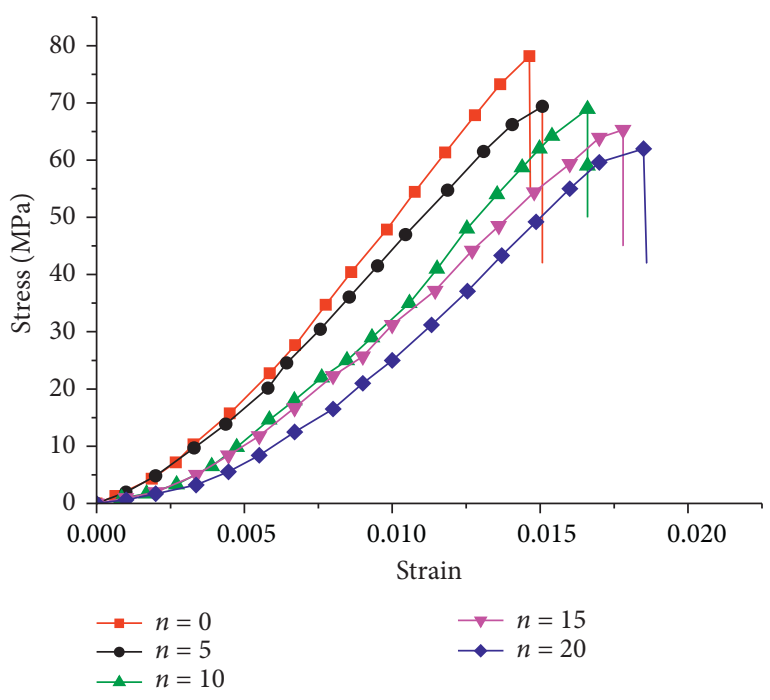

FIGURE 5: Stress-strain curve of red sandstone under the uniaxial compression.

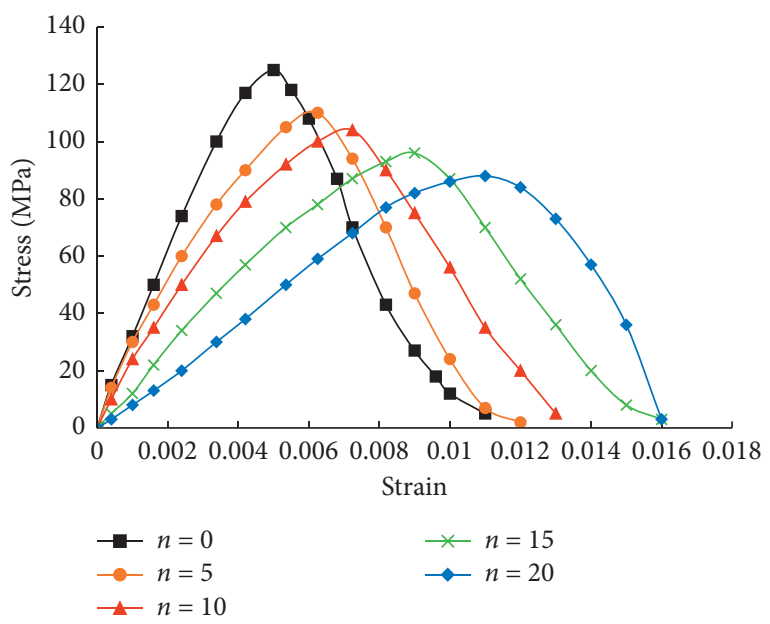

FIgURE 6: Dynamic compression stress-strain curve of red sandstone. peak strain, with the propagation of internal cracks in the rock, the increased rate of stress slows down. The stress increases nonlinearly with the increase of strain, and the stress-strain curve presents plastic characteristics until the yield failure occurs.

The dynamic compressive strength and elastic modulus of rock samples are different under the same impact pressure. With the increase of wetting-drying cycles, the dynamic compressive strength and dynamic elastic modulus of rock samples decrease, while the yield strain increases.

3.2.2. Analysis of Strain Rate Effect. The strain rate is taken as abscissa and dynamic compressive strength as ordinate, and then the scatter diagram of dynamic compressive strength strain rate is drawn, as shown in Figure 7. It can be seen that the dynamic compressive strength of red sandstone is significantly affected by the strain rate. Under the same number of wetting-drying cycles, with the increase of strain rate, the dynamic compressive strength of red sandstone gradually increases. Compared with the rock samples after wetting-drying cycles, the strain rate enhancement effect of samples without wetting-drying cycles is the most obvious, and the sensitivity of strain rate decreases with the increase of wetting-drying cycles. The relationship between the dynamic strength and strain rate of red sandstone is fitted by an exponential function, as shown in equation (1). The $\sigma_{d}$ is the dynamic compressive strength, $\dot{\varepsilon}$ is the strain rate, and $n$ is the number of wetting-drying cycles.

$$
\left\{\begin{array}{l}
\sigma_{d}=46.64+27.307 e^{0.013 \dot{\varepsilon}}, \\
R^{2}=0.987,(n=0), \\
\sigma_{d}=47.80+20.786 e^{0.014 \dot{\varepsilon}} \\
R^{2}=0.989,(n=5), \\
\sigma_{d}=52.20+14.770 e^{0.016 \dot{\varepsilon}}, \\
R^{2}=0.982,(n=10), \\
\sigma_{d}=52.67+10.819 e^{0.017 \dot{\varepsilon}} \\
R^{2}=0.988,(n=15), \\
\sigma_{d}=52.37+7.319 e^{0.019 \dot{\varepsilon}} \\
R^{2}=0.996,(n=20) .
\end{array}\right.
$$
follows:

The form of fitting equation (1) can be summarized as

$$
\sigma_{d}=\sigma_{0}+A e^{b \dot{\varepsilon}}
$$

Because the strain rate effect of the dynamic compressive strength of red sandstone is coupled with the wetting-drying cycles, the parameters in the fitting equation change with the number of wetting-drying cycles. Figure 8 shows the changes in each parameter with the number of wetting-drying cycles.

The relationship between the parameters and the number of wetting-drying cycles can be linearly fitted as follows: 


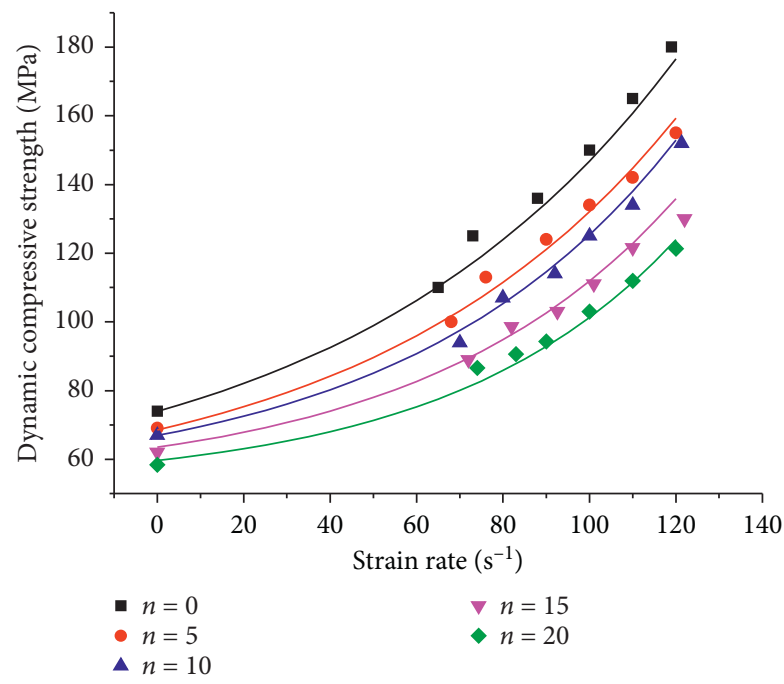

FIGURE 7: Fitting curves of dynamic compressive strength versus strain rate.

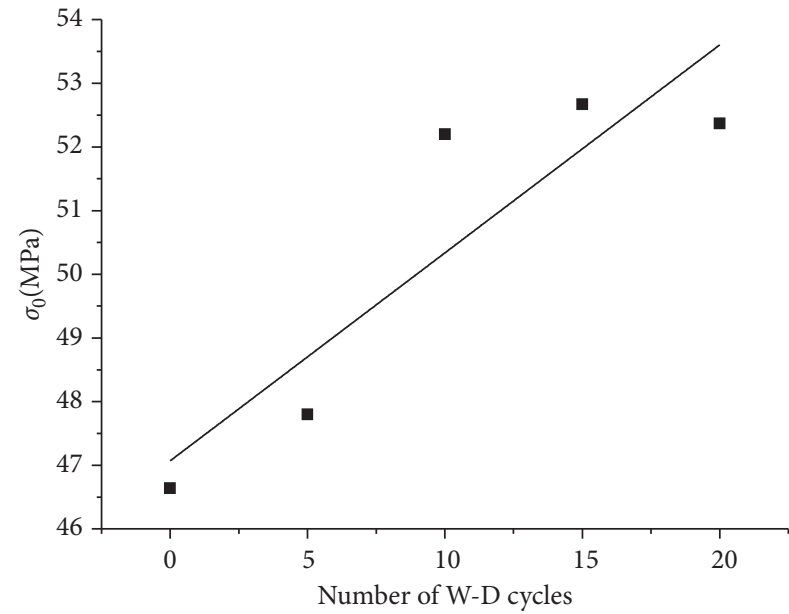

(a)

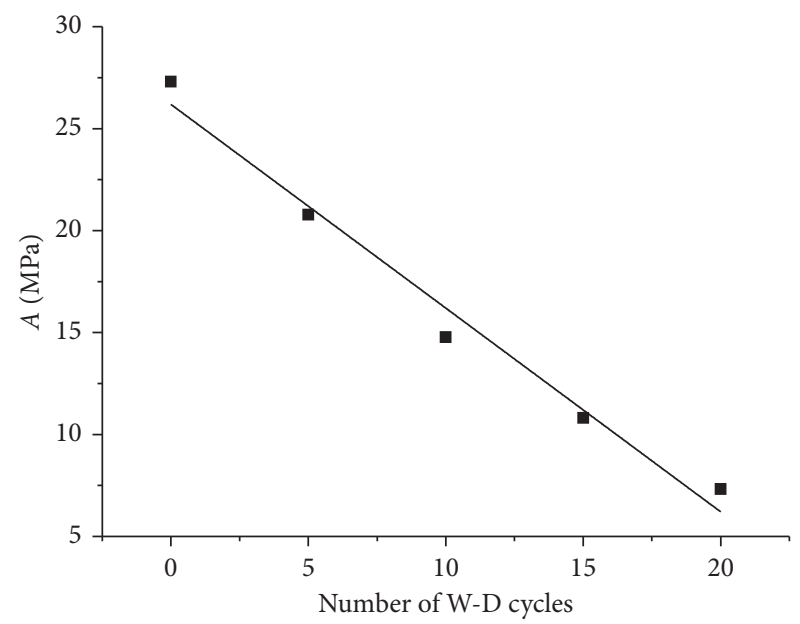

(b)

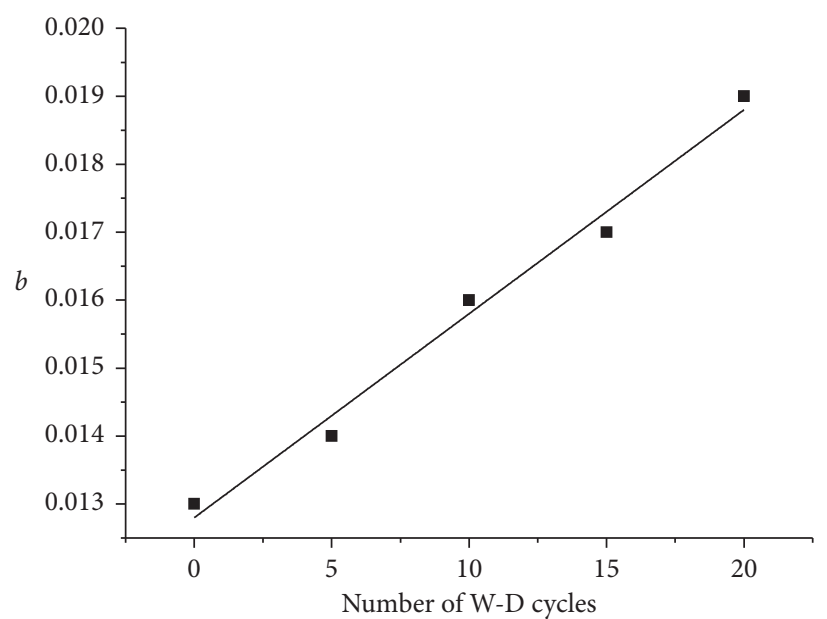

(c)

Figure 8: Changing rules of parameters versus the number of wetting-drying cycles of fitted equations. (a) Parameter $\sigma_{0}$. (b) Parameter $A$. (c) Parameter $b$. 


$$
\left\{\begin{array}{l}
\sigma_{0}=47.07+0.327 n \\
R^{2}=0.804 \\
A=26.19-0.999 n \\
R^{2}=0.981 \\
b=0.013+0.0003 n \\
R^{2}=0.987
\end{array}\right.
$$

Considering the combined effect of wetting-drying cycles and strain rate, the calculation equation for the dynamic compressive strength of red sandstone can be obtained by substituting equation (3) into equation (2).

Dynamic intensity enhancement factor $(D I F)$ is used to measure the increase of compressive strength of rock under impact load. This index is the ratio of dynamic compressive strength to static compressive strength. As shown in Figure 9, with the increase of strain rate, the DIF of red sandstone increases continuously. In other words, the higher the strain rate, the greater the enhancement range of dynamic compressive strength of red sandstone, and the more obvious the sensitivity of the strain rate. At the same strain rate, compared with the rock sample after wetting-drying cycles, the DIF of red sandstone without wetting-drying cycles is the largest. It indicates that the wetting-drying cycle reduces the strain rate sensitivity of red sandstone, and the larger the number of the wettingdrying cycles, the smaller the increase of dynamic compressive strength of red sandstone.

3.2.3. Analysis of Wetting-Drying Cycle Effect. In the SHPB test, the strain rate effect is coupled with the wetting-drying cycle effect. To reveal the effect of wetting-drying cycles on the red sandstone, the rock sample should be in the same strain rate condition. According to the strain rate range of the abovementioned tests, six strain rates of $70,80,90,100$, 110 , and $120 \mathrm{~s}^{-1}$ are used to draw the curve of dynamic compressive strength of the red sandstone versus the number of wetting-drying cycles under different strain rates, as shown in Figure 10.

As shown in Figure 10, when the strain rate is the same, the dynamic compressive strength of red sandstone gradually decreases with the increase of wetting-drying cycles. It indicates that the wetting-drying cycles have a significant deterioration effect on the dynamic strength of red sandstone. The higher the strain rate, the faster the decrease of dynamic compressive strength, and the stronger the sensitivity to wetting-drying cycles will be.

\subsubsection{Dynamic Fracture Characteristics of Red Sandstone.} Figure 11 shows the failure modes of red sandstone samples after impact with different wetting-drying cycles. It can be seen that the samples have been damaged under various conditions, but there are significant differences in the degree of fragmentation. Besides, the fracture morphology is affected by the number of wetting-drying cycles and the strain rate. Due to the limitation of space, partial failure modes of some rock samples are selected in this paper: (1) failure

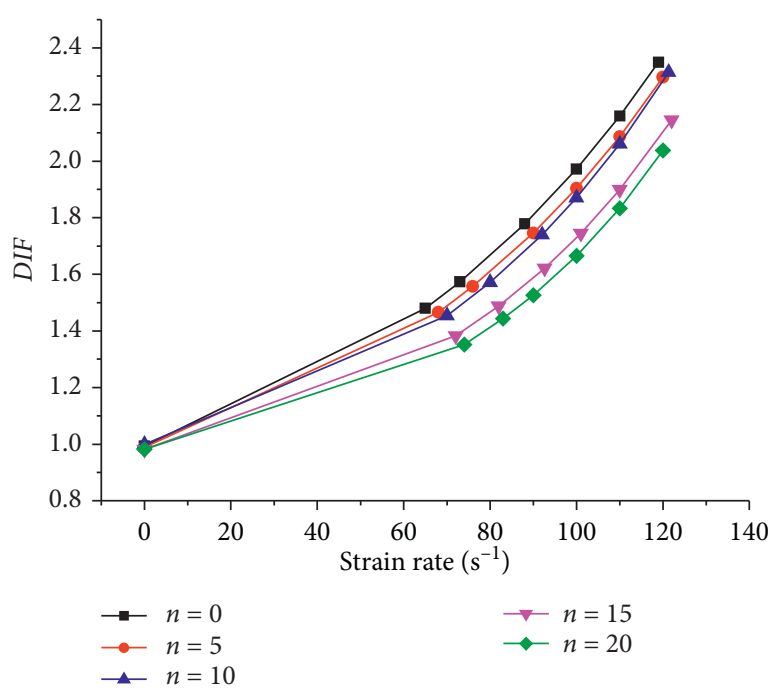

FIGURE 9: Curve of DIF of red sandstone versus strain rate.

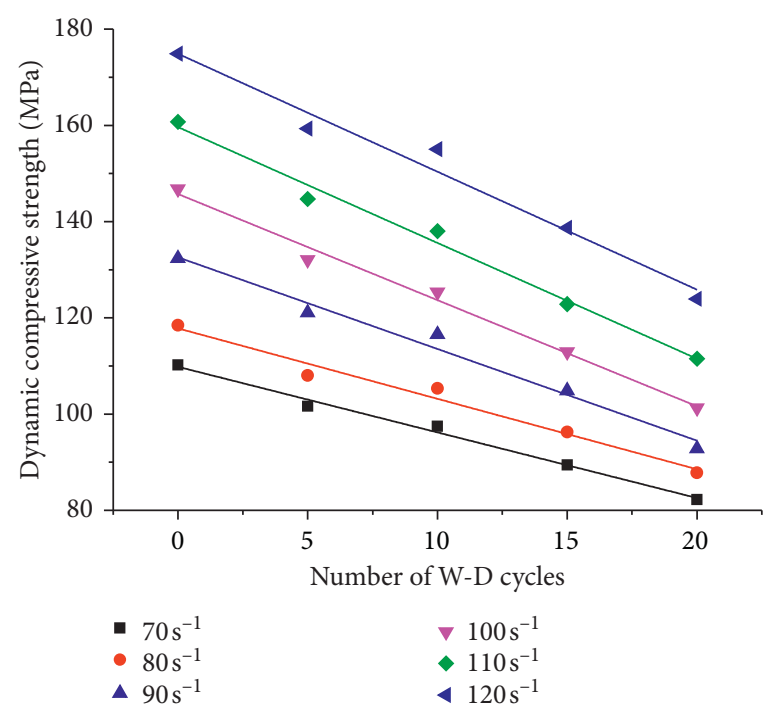

Figure 10: Curve of dynamic compressive strength of red sandstone versus wetting-drying cycles.

modes of the red sandstone under different wetting-drying cycles at the strain rate of $90 \mathrm{~s}^{-1}$ (due to the heterogeneity of the rock, the deviation of the strain rate is controlled within a small range, and the identical strain rate cannot be ensured); (2) failure modes of red sandstone under 10 wetting-drying cycles at different strain rates $\left(90-120 \mathrm{~s}^{-1}\right)$. As shown in Figure 11, at the same strain rate, the more the wettingdrying cycles, the greater the fragmentation degree of the rock sample; when the number of wetting-drying cycles is the same, with the increase of strain rate, the fragmentation degree of the rock sample tends to increase.

Rock failure is the result of continuous initiation, expansion, aggregation, and final penetration of internal cracks. From microscopic development to macroscopic crushing, this process is also a process of energy dissipation with fractal characteristics and good self-similarity [32-34]. 


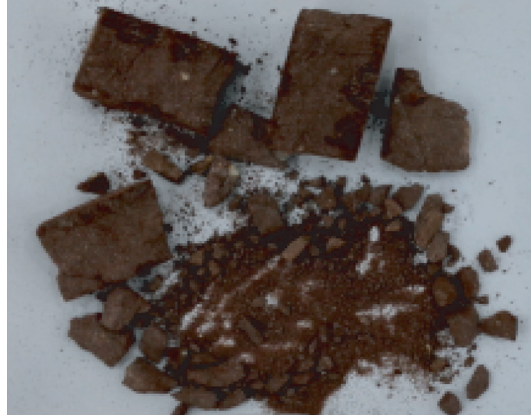

(a)

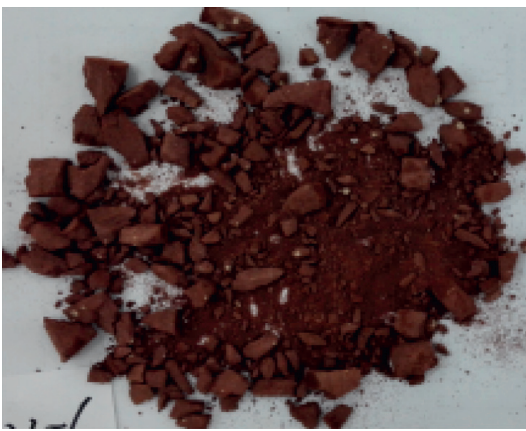

(d)

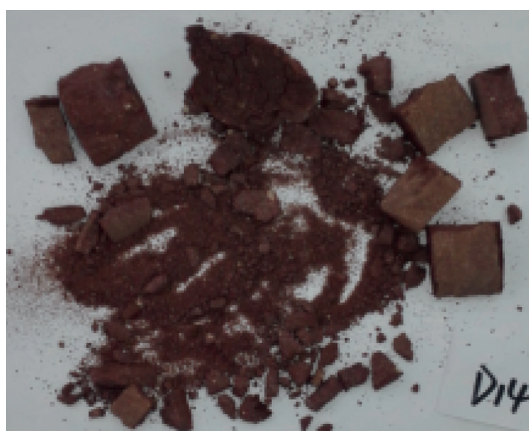

(g)

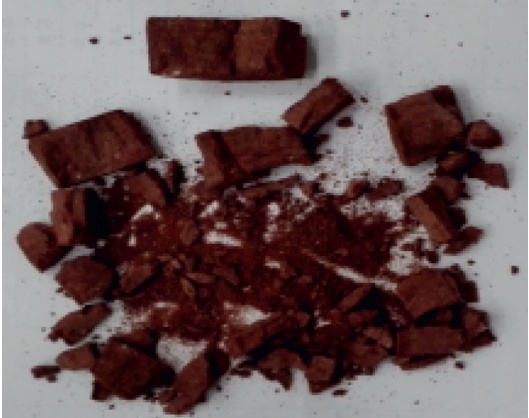

(b)

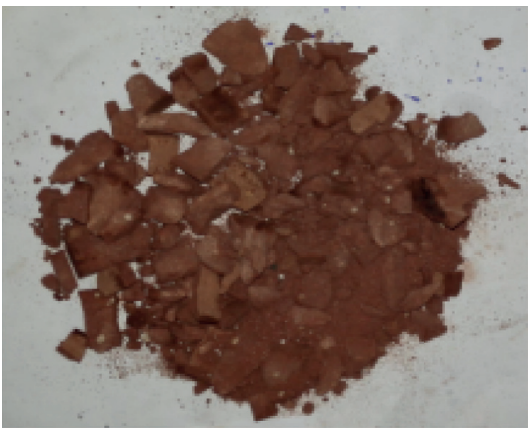

(e)

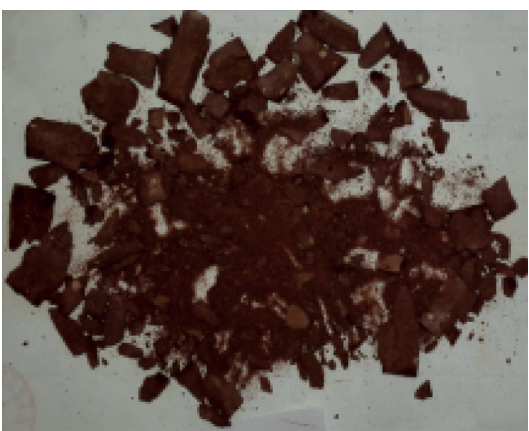

(h)

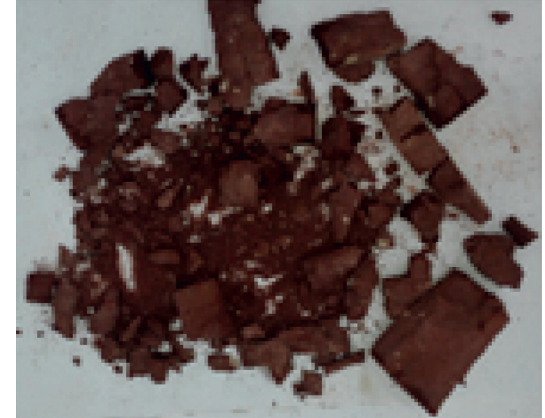

(c)

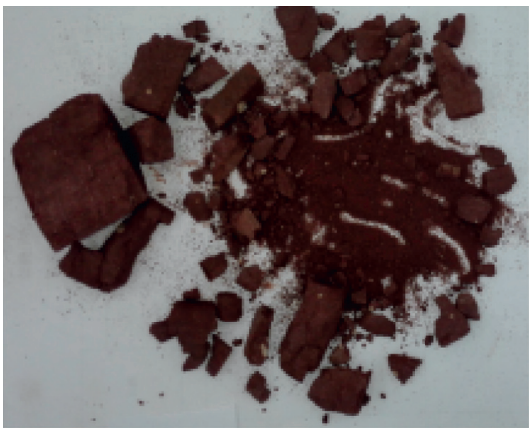

(f)

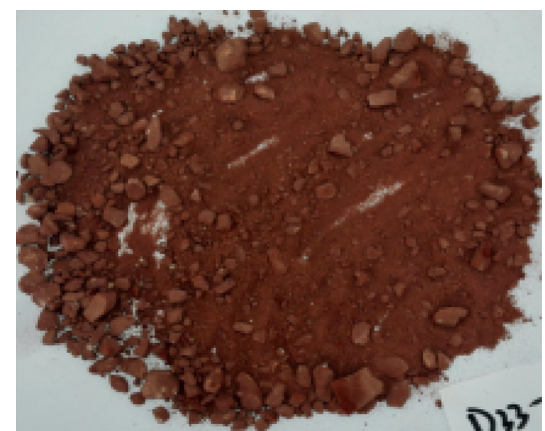

(i)

FiguRe 11: Failure modes of specimens with different strain rates and number of wetting-drying cycles. (a) $\left(n=0, \varepsilon=87 \mathrm{~s}^{-1}\right),(\mathrm{b})(n=5$, $\left.\varepsilon=88 \mathrm{~s}^{-1}\right)$, (c) $\left(n=10, \varepsilon=90 \mathrm{~s}^{-1}\right),(\mathrm{d})\left(n=15, \varepsilon=92 \mathrm{~s}^{-1}\right)$, (e) $\left(n=20, \varepsilon=93 \mathrm{~s}^{-1}\right),(\mathrm{f})\left(n=10, \varepsilon=91 \mathrm{~s}^{-1}\right),(\mathrm{g})\left(n=10, \varepsilon=102 \mathrm{~s}^{-1}\right),(\mathrm{h})(n=10$, $\left.\varepsilon=112 \mathrm{~s}^{-1}\right)$, and (i) $\left(n=10, \varepsilon=124 \mathrm{~s}^{-1}\right)$.

Through a lot of theoretical analysis and experimental research, many statistical functions about the distribution of rock fragmentation have been obtained. The massequivalent size distribution function is widely used and expressed as follows [35-37]:

$$
\begin{aligned}
D & =3-b, \\
b & =\frac{\lg \left(M_{R} / M\right)}{\lg R} .
\end{aligned}
$$

In equations (4) and (5), $D$ is the fractal dimension and $b$ is the rock block distribution parameter, that is, the slope of the straight line drawn under the double logarithm $\lg R-\lg \left(M_{R} / M\right)$ coordinate. $M_{R}$ is the cumulative mass of the fragments with a diameter less than $R, M$ is the total mass of the sample, and $R$ is the size of the sieve mesh. According to the size characteristics of fragments produced by the SHPB dynamic tensile test of red sandstone, $0.25,0.5,1,2,5,10,15$, and $20 \mathrm{~mm}$ standard square hole sieves are selected, and the broken particles are divided into 9 grades, including $0-0.25$, $0.25-0.5,0.5-1,1-2,2-5,5-10,10-15,15-20$, and $20-50$. The mass of retained fragments in each grade of sieve hole is measured by the high sensitivity electronic scale. By substituting the mass parameters into the above equations, the fractal dimension of red sandstone fragments under different conditions is obtained, and the scatter diagram of strain rate fractal dimension under different wetting-drying cycles is drawn, as shown in Figure 12.

As shown in Figure 12, within the range of test strain rate, the fractal dimension $D$ of rock sample fragments is in the range of 2.02-2.80. With the increase of strain rate, the fractal dimension of fragments gradually increases. It indicates that the higher the fragmentation degree, the greater 


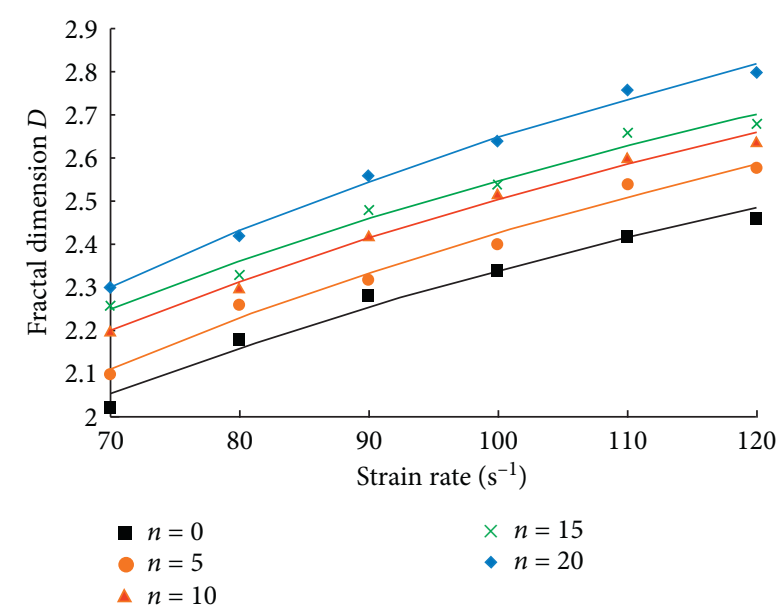

FIGURE 12: Relationship between fractal dimension and strain rate after different wetting-drying cycles.

the impact load required, which is also consistent with the experimental phenomenon in Figure 11. Under different wetting-drying cycles, the fractal dimension of rock fragments increases logarithmically with the strain rate. The fitting equation is shown in Table 2. At the same strain rate, the more the wetting-drying cycles, the larger the fractal dimension of fragments, and the higher the fragmentation degree.

\subsubsection{Analysis of Damage Deterioration Mechanism.} From the abovementioned research results, it can be seen that the wetting-drying cycles have a certain degradation effect on the static and dynamic mechanical properties of red sandstone, and with the increase of wetting-drying cycles, the deterioration of red sandstone is a progressive process of damage accumulation. Because the wetting-drying cycles process is mainly composed of two parts: the soaking process (from drying to wetting) and the drying process (from wetting to drying), in this complex process of wetting and drying, not only the change of rock moisture content is involved but also the change of temperature. In the process of rock soaking, mineral particles are cooled and contracted, and the contact stress between particles is mainly tensile stress. In the drying process of rock, mineral particles are expanded, and compressive stress is the main contact stress between particles. Under the repeated action of wettingdrying cycles, the tension and compression between mineral particles are alternated continuously. As a result, cracks are generated at the interface of particles, and the bonding effect between particles decreases in varying degrees [38]. In addition, the infiltration of water molecules can also lead to the dissolution of cementitious materials and the hydrolysis of some minerals in red sandstone, which is one of the reasons for the cementation weakening between particles. With the expansion and penetration of fractures, the infiltration path and distance of water molecules gradually increase, resulting in more tension and compression effect of mineral particles and the new generation of fractures. When the internal erosion of rock by wetting-drying cycles reaches a certain
TABLE 2: Fitting results of fractal dimension versus strain rate of red sandstone.

\begin{tabular}{lcc}
\hline $\begin{array}{l}\text { Number of wetting- } \\
\text { drying cycles }\end{array}$ & $\begin{array}{c}\text { Fractal dimension-strain rate } \\
\text { equation }\end{array}$ & $R^{2}$ \\
\hline 0 & $D=0.802 \ln \dot{\varepsilon}-1.355$ & 0.979 \\
5 & $D=0.884 \ln \dot{\varepsilon}-1.645$ & 0.982 \\
10 & $D=0.855 \ln \dot{\varepsilon}-1.433$ & 0.993 \\
15 & $D=0.84 \ln \dot{\varepsilon}-1.32$ & 0.979 \\
20 & $D=0.962 \ln \dot{\varepsilon}-1.783$ & 0.993 \\
\hline
\end{tabular}

degree, the internal microcracks and microholes are gradually transformed into macrocracks and macroholes, and the macrodamage is developed continuously. Finally, the mechanical properties of the samples continuously deteriorate.

\section{Conclusions}

Based on the static and dynamic mechanical tests of red sandstone, the dynamic compression mechanical properties of rock under the action of wetting-drying cycles are systematically studied in this paper. The relationship among the dynamic compressive strength of red sandstone, strain rate, and the number of wetting-drying cycles are analyzed. The conclusions are obtained as follows:

(1) With the increase of strain rate, the dynamic compressive strength of red sandstone increases gradually, and it is significantly affected by the strain rate. The sensitivity of the strain rate of dynamic compressive strength of red sandstone decreases with the increase of wetting-drying cycles, and the effect of strain rate of rock samples without wetting-drying cycles is the most significant.

(2) At the same strain rate, the dynamic tensile strength of red sandstone decreases gradually with the increase of wetting-drying cycles. Considering the combined influence of wetting-drying cycles and strain rate, the calculation equation of dynamic compressive strength of red sandstone is given.

(3) The fractal characteristics of dynamic compressive fragments of red sandstone are significant, and the fractal dimension is 2.02-2.80. At the same wettingdrying cycles, the fractal dimension increases logarithmically with the strain rate. At the same strain rate, the fractal dimension increases with the increasing number of wetting-drying cycles.

(4) The wetting-drying cycles weaken the bonding effect among mineral particles of rock, and the damage accumulation degree increases with the increase of wetting-drying cycles. This is the fundamental reason for the decline of the dynamic mechanical properties of red sandstone.

\section{Data Availability}

The data used to support the findings of this study are included within the article. 


\section{Conflicts of Interest}

The authors declare that they have no conflicts of interest.

\section{Acknowledgments}

The work was supported by the National Natural Science Foundation of China (51323004, 51704281, and 52004105), Xuzhou Science and Technology Project (KC19012 and KC20199), General Projects of Natural Science Research in Universities of Jiangsu Province (19KJB130004, 20KJB410002, and 20KJB170024), and Doctor Special Research Fund of Jiangsu Collaborative Innovation Center for Building Energy Saving and Construct Technology (SJXTBS1701 and SJXTBS1705).

\section{References}

[1] M. L. Lin, F. S. Jeng, L. S. Tsai, and T. H. Huang, "Wetting weakening of tertiary sandstones-microscopic mechanism," Environment Geology, vol. 48, pp. 265-275, 2005.

[2] X. Cai, Z. Zhou, L. Tan, H. Zang, and Z. Song, "Water saturation effects on thermal infrared radiation features of rock materials during deformation and fracturing," Rock $\mathrm{Me}$ chanics and Rock Engineering, vol. 53, no. 11, 2020.

[3] P. A. Hale and A. Shakoor, "A laboratory investigation of the effects of cyclic heating and cooling, wetting and drying, and freezing and thawing on the compressive strength of selected sandstones," Environmental and Engineering Geoscience, vol. 9, no. 2, pp. 117-130, 2003.

[4] D. Ma, J. Zhang, H. Duan et al., "Reutilization of gangue wastes in underground backfilling mining: overburden aquifer protection," Chemosphere, vol. 264, no. 1, Article ID 128400, 2021.

[5] A. Momeni, S. S. Hashemi, G. R. Khanlari, and M. Heidari, "The effect of weathering on durability and deformability properties of granitoid rocks," Bulletin of Engineering Geology and the Environment, vol. 76, no. 3, pp. 1037-1049, 2017.

[6] C. Gökceoglu, R. Ulusay, and H. Sönmez, "Factors affecting the durability of selected weak and clay-bearing rocks from Turkey, with particular emphasis on the influence of the number of drying and wetting cycles," Engineering Geology, vol. 57, pp. 215-237, 2000.

[7] D. Ma, H. Duan, W. Liu, X. Ma, and M. Tao, "Water-sediment two-phase flow inrush hazard in rock fractures of overburden strata during coal mining," Mine Water and the Environment, vol. 39, no. 2, pp. 308-319, 2020.

[8] C. Apollaro, L. Marini, T. Critelli, and R. De Rosa, "The standard thermodynamic properties of vermiculites and prediction of their occurrence during water-rock interaction," Applied Geochemistry, vol. 35, pp. 264-278, 2013.

[9] P. Alt-Epping, L. W. Diamond, M. O. Häring, F. Ladner, and D. B. Meier, "Prediction of water-rock interaction and porosity evolution in a granitoid-hosted enhanced geothermal system, using constraints from the $5 \mathrm{~km}$ Basel-1 well," Applied Geochemistry, vol. 38, pp. 121-133, 2013.

[10] P. D. Sumner and M. J. Loubser, "Experimental sandstone weathering using different wetting and drying moisture amplitudes," Earth Surface Processes and Landforms, vol. 33, no. 6, pp. 985-990, 2008.

[11] Z. A. Erguler and R. Ulusay, "Water-induced variations in mechanical properties of clay-bearing rocks," International
Journal of Rock Mechanics and Mining Sciences, vol. 46, no. 2, pp. 355-370, 2009.

[12] D. Ma, H. Duan, Q. Zhang et al., "A numerical gas fracturing model of coupled thermal, flowing and mechanical effects," Computers, Materials \& Continua, vol. 65, no. 3, pp. 21232141, 2020.

[13] T. P. Gautam and A. Shakoor, "Slaking behavior of claybearing rocks during a one-year exposure to natural climatic conditions," Engineering Geology, vol. 166, pp. 17-25, 2013.

[14] J. Zhao, Y. X. Zhou, A. M. Hefny et al., "Rock dynamics research related to cavern development for Ammunition storage," Tunnelling and Underground Space Technology, vol. 14 , no. 4 , pp. 513-526, 1999.

[15] P. Wang, J. Xu, S. Liu, and H. Wang, "Dynamic mechanical properties and deterioration of red-sandstone subjected to repeated thermal shocks," Engineering Geology, vol. 212, pp. 44-52, 2016.

[16] D. Ma, H. Duan, X. Li, Z. Li, Z. Zhou, and T. Li, "Effects of seepage-induced erosion on nonlinear hydraulic properties of broken red sandstones," Tunnelling and Underground Space Technology, vol. 91, Article ID 102993, 2019.

[17] A. M. Ruhbin and T. J. Ahrens, "Dynamic tensile-failureinduced velocity deficits in rock," Geophysical Research Letters, vol. 18, no. 2, pp. 219-222, 1991.

[18] B. Wang, X. Li, and T. Yin, "Split hopkinson pressure bar(SHPB) experiments on dynamic strength of watersaturated sandstone," Chinese Journal of Rock Mechanics and Engineering, vol. 29, no. 5, pp. 1003-1009, 2010, in Chinese.

[19] X. Cai, Z. Zhou, H. Zang, and Z. Song, "Water saturation effects on dynamic behavior and microstructure damage of sandstone: phenomena and mechanisms," Engineering Geology, vol. 276, Article ID 105760, 2020.

[20] X. Cai, Z. Zhou, and X. Du, "Water-induced variations in dynamic behavior and failure characteristics of sandstone subjected to simulated geo-stress," International Journal of Rock Mechanics and Mining Sciences, vol. 130, Article ID 104339, 2020.

[21] Z. Zhou, X. Cai, W. Cao, X. Li, and C. Xiong, "Influence of water content on mechanical properties of rock in both saturation and drying processes," Rock Mechanics and Rock Engineering, vol. 49, no. 8, pp. 3009-3025, 2016.

[22] H. Wang, J. Xu, and P. Wang, "Mechanical properties and energy mechanism of red sandstone under hydro-dynamic coupling effect," Rock and Soil Mechanics, vol. 37, no. 10, pp. 2861-2868, 2016, in Chinese.

[23] Z. L. Zhou, X. Cai, and L. Chen, "Influence of cyclic wetting and drying on physical and dynamic compressive properties of sandstone," Engineering Geology, vol. 220, pp. 1-12, 2017.

[24] Z. Zhou, X. Cai, D. Ma, L. Chen, S. Wang, and L. Tan, "Dynamic tensile properties of sandstone subjected to wetting and drying cycles," Construction and Building Materials, vol. 182, pp. 215-232, 2018.

[25] Q. B. Zhang and J. Zhao, "A review of dynamic experimental techniques and mechanical behaviour of rock materials," Rock Mechanics and Rock Engineering, vol. 47, no. 4, pp. 1411-1478, 2014.

[26] F. Dai and K. W. Xia, "Laboratory measurements of the rate dependence of the fracture toughness anisotropy of Barre granite," International Journal of Rock Mechanics and Mining Sciences, vol. 60, pp. 57-65, 2013.

[27] F. Dai, S. Huang, K. Xia, and Z. Tan, "Some fundamental issues in dynamic compression and tension tests of rocks 
using split hopkinson pressure bar," Rock Mechanics and Rock Engineering, vol. 43, no. 6, pp. 657-666, 2010.

[28] Z. Zhou, X. Li, A. Liu, and Y. Zou, "Stress uniformity of split hopkinson pressure bar under half-sine wave loads," International Journal of Rock Mechanics and Mining Sciences, vol. 48, no. 4, pp. 697-701, 2011.

[29] Y. X. Zhou and J. Zhao, Advances in Rock Dynamics and Applications, CRC Press, Boca Raton, FL, USA, 2011.

[30] Y. X. Zhou, K. Xia, X. B. Li et al., "Suggested methods for determining the dynamic strength parameters and mode-I fracture toughness of rock materials," International Journal of Rock Mechanics and Mining Sciences, vol. 49, pp. 105-112, 2012.

[31] The National Standard Compilation Groups of People's Republic of China, GB/T 23561.5-2009 Methods for Determining the Physical and Mechanical Properties of Coal and Rock, Standards Press of China, Beijing, China, 2009, in Chinese.

[32] H. Xie, Fractals in Rock Mechanics, A A Balkema Publishers, Amsterdam, The Netherlands, 1993.

[33] A. Carpinteri, G. Lacidogna, and N. Pugno, "Scaling of energy dissipation in crushing and fragmentation: a fractal and statistical analysis based on particle size distribution," International Journal of Fracture, vol. 129, no. 2, pp. 131-139, 2004.

[34] D. Ma, H. Duan, J. Liu, X. Li, and Z. Zhou, "The role of gangue on the mitigation of mining-induced hazards and environmental pollution: an experimental investigation," Science of the Total Environment, vol. 664, pp. 436-448, 2019.

[35] S. Y. Li, T. M. He, and X. C. Yin, Introduction of Rock Fracture Mechanics, China University of Science and Technology Press, Hefei, China, 2010.

[36] W. Mu, L. Li, T. Yang, L. Yao, and S. Wang, "Numerical calculation and multi-factor analysis of slurry diffusion in an inclined geological fracture," Hydrogeology Journal, vol. 28, no. 3, pp. 1107-1124, 2020.

[37] Y. Deng, M. Chen, Y. Jin, and D. Zou, “Theoretical analysis and experimental research on the energy dissipation of rock crushing based on fractal theory," Journal of Natural Gas Science and Engineering, vol. 33, pp. 231-239, 2016.

[38] X. Cai, Z. Zhou, L. Tan, H. Zang, and Z. Song, "Fracture behavior and damage mechanisms of sandstone subjected to wetting-drying cycles," Engineering Fracture Mechanics, vol. 234, Article ID 107109, 2020. 